\title{
ESTRUTURA DA VEGETAÇÃO EM REMANESCENTES DE CAATINGA COM DIFERENTES HISTÓRICOS DE PERTURBAÇÃO EM CAJAZEIRINHAS (PB) ${ }^{1}$
}

\author{
ALAN CAUÊ DE HOLANDA ${ }^{2 *}$, FRANCISCO TADEU DANTAS LIMA ${ }^{3}$, BRENO MOURA SILVA $^{3}$, RAMON \\ GUANAES DOURADO ${ }^{3}$, ALLYSON ROCHA ALVES ${ }^{2}$
}

\begin{abstract}
RESUMO - A Caatinga é um dos biomas menos conhecidos em termos de estrutura e composição florística, aspecto preocupante, pois sofre um intenso processo de antropização. Partindo desse princípio, foi realizado um levantamento fitossociológico da vegetação adulta e regeneração natural em áreas com diferentes históricos de perturbação. Para amostragem do componente arbustivo/arbóreo adulto e regeneração natural instalou-se, de forma sistemática, 18 unidades amostrais em cada área (Ambiente I e Ambiente II), com dimensões de 10 x 25 m e $10 \times 5$ m, respectivamente. Foram inventariados os indivíduos adultos com CAP $\geq 6,0 \mathrm{~cm}$, e para regeneração natural mensurados os indivíduos com altura superior a $0,5 \mathrm{~m} \mathrm{e} C N B<6,0 \mathrm{~cm}$. No ambiente II foram amostrados 1155 indivíduos, pertencentes a 6 famílias e 12 espécies, e no ambiente I amostrados 286 indiví-

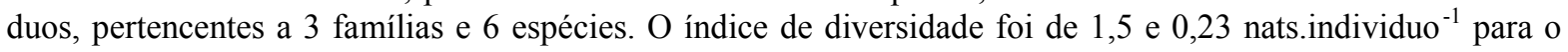
ambiente II e ambiente I, respectivamente. Foram amostrados 636 indivíduos na regeneração natural, sendo 360 no ambiente I e 276 no ambiente II. O índice de diversidade da regeneração natural para os ambientes I e II foram de 1,21 e 0,8 nats.ind ${ }^{-1}$, respectivamente. Concluiu-se que as ações antrópicas foram capazes de mudar de maneira significativa a estrutura da vegetação e diversidade de espécies nos dois ambientes.
\end{abstract}

Palavras-chave: Antropização. Levantamento Fitossociológico. Remanescente Savana.

\section{VEGETATION STRUCTURE CAATINGA IN REMAINING FROM DIFFERENT WITH HISTORICAL DISTURBANCE IN THE REGION OF CAJAZEIRINHAS - PB}

\begin{abstract}
The Caatinga is one of the least known biomes in terms of structure and floristic composition, worrying aspect because it undergoes an intense process of human disturbance. With this assumption, we carried out a phytosociological survey of adult vegetation and natural regeneration in areas with different histories of disturbance. For a sampling of the shrub/adult tree and natural regeneration, settled in a systematic, 18 sampling units in each area (Habitat I and Habitat II), with dimensions of $10 \times 25 \mathrm{~m}$ and $10 \times 5$ m respectively. Individuals were surveyed adults with $\mathrm{CAP} \geq 6.0 \mathrm{~cm}$, and natural regeneration measured the individuals taller than $0.5 \mathrm{~m}$ and CNB $<6.0 \mathrm{~cm}$. Habitat II in the were sampled 1155 individuals belonging to 6 families and 12 species, and the habitat I was sampled 286 individuals belonging to three families and six species. The diversity

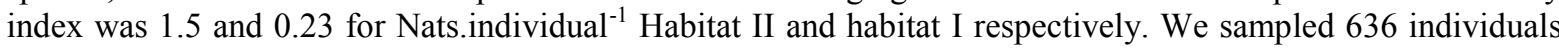
in natural regeneration, being habitat I in 360 and 276 in the Habitat II. The diversity index of natural regeneration for the Habitat II and habitat I were 1.21 and 0.8 Nats.individual $^{-1}$. It was concluded that human activities were able to change the vegetation structure and species diversity in both habitats significantly.
\end{abstract}

Keywords: Anthropization. Survey Phytosociological. Remnant Savannah.

\footnotetext{
*Autor para correspondência

${ }^{1}$ Recebido para publicação em 12/05/2014; aceito em 30/07/2015.

Trabalho de Conclusão de Curso de graduação em agronomia.

${ }^{2}$ Departamento de Ciências Vegetais, UFERSA, CEP 59.625-900, Mossoró (RN); alan.holanda@ufersa.edu.br.

${ }^{3}$ Unidade Acadêmica de Ciências Agrárias, CCTA, UFCG, Campus Pombal, CEP 58.840-000, Pombal (PB).
} 


\section{INTRODUÇÃO}

O domínio do bioma Caatinga abrange cerca de 900 mil $\mathrm{Km}^{2}$, correspondendo a aproximadamente $54 \%$ da região Nordeste. Está compreendido entre os paralelos de $2^{\circ} 54^{\prime} \mathrm{S}$ a $17^{\circ} 21^{\prime} \mathrm{S}$ e envolvem áreas dos Estados do Ceará, Rio Grande do Norte, Paraíba, Pernambuco, Alagoas, Sergipe, sudoeste do Piauí, partes do interior da Bahia e do norte de Minas Gerais (ANDRADE et al., 2005).

A Caatinga constitui um complexo vegetacional que reúne ambientes muito distintos, fisionomias variadas e flora diversificada, cujo conhecimento se encontra em curso (ANDRADE et al., 2011). Andrade-Lima (1989) descreve que a Caatinga deve, antes de tudo, ser aceita como um conjunto de paisagens da floresta caducifólia, com boa frequência de espinhosas.

A morfologia, a fisiologia e a ecologia das plantas da Caatinga determinam as características vegetacionais do bioma (COSTA et al., 2010). Segundo os autores, as espécies possuem caráter comportamental e fisiológico em relação às características do meio, determinando as peculiaridades e ajustamento das plantas com as características físicas do meio em questão. Os processos biológicos, dado o comando genético, selecionam peculiaridades adaptativas, tornando a flora endêmica da Caatinga compatível com as condições severas a que estão sujeitos os táxons. Essas peculiaridades adaptativas da vegetação são determinadas, principalmente, pela temperatura e disponibilidade de água. O estresse hídrico é um dos fatores mais limitantes de produtividade e distribuição geográfica das espécies vegetais.

A ação do homem em busca de solos mais férteis para a prática agrícola e agropecuária vem sendo considerada uma das principais causas que levam as áreas da Caatinga a serem devastadas, deixando o solo exposto e suscetível ao processo erosivo, à desertificação e levando ao desaparecimento de inúmeras espécies vegetais e/ou animais. A degradação da Caatinga pela ação antrópica acaba por comprometer cada vez mais os recursos naturais e a sustentabilidade deste bioma (DANTAS et al., 2010).

Diante do exposto, Santana (2005) descreve que há alguns anos a comunidade científica tem se preocupado com a situação do bioma Caatinga, especialmente quanto a manutenção da sua biodiversidade vegetal e desertificação, o que implica necessariamente no aumento de levantamentos florísticos e fitossociológicos, de modo contínuo e regular. Esses estudos permitirão monitorar as eventuais alterações na estrutura da vegetação e fornecer subsídios que possibilitem o aumento do conhecimento sobre $o$ bioma, sendo possível estabelecer ações que preservem seu patrimônio genético e sua utilização de forma racional.

Partindo desse princípio, foi realizado um levantamento fitossociológico da vegetação arbustivo/arbórea adulta e regeneração natural em áreas com diferentes históricos de perturbação causados por fatores antrópicos, possibilitando identificar quais atividades humanas interferiram em maior intensidade na dinâmica da estrutura da vegetação em área de Caatinga no município Cajazeirinhas (PB).

\section{MATERIAIS E MÉTODOS}

\section{Caracterização das áreas}

O experimento foi conduzido em uma área de Caatinga que se encontra com diferentes históricos de perturbação da vegetação e estão situadas na Fazenda São Francisco, localizada no município de Cajazeirinhas (PB), sob as coordenadas geográficas $06^{\circ} 57^{\prime} 40^{\prime \prime}$ latitude sul e $37^{\circ} 48^{\prime} 22^{\prime \prime}$ longitude oestes. O remanescente possui uma área de 30 ha. E os solos predominantes da área experimental são LUVISSOLOS em associação com NEOSSOLOS LITÓLICOS (EMBRAPA, 2006).

Segundo classificação de Köeppen, o clima da região se enquadra no tipo BSh, semiárido quente, com médias térmicas anuais superiores a $25{ }^{\circ} \mathrm{C}$ e pluviosidade média anual inferior a $1000 \mathrm{~mm}$, com chuvas irregulares (CORRÊA et al., 2003).

\section{Histórico das áreas}

A primeira área de estudo (Ambiente I) foi suprimida há 12 anos para extração de madeira, utilizada principalmente para construção e manutenção de cercas e produção de carvão. Após a exploração foi implantada a prática de Agricultura de Queima e Roça (AQR), onde se introduziu lavouras de milho por dois anos seguidos, e observando o acesso a tecnologias e falta de investimentos a área foi posteriormente abandonada e destinada a atividades pastoris (criação de ovinos e bovinos) e retirada de estacas para manutenção de cercados.

O segundo local de estudo (Ambiente II) é um remanescente de Caatinga localizado nas adjacências da área citada acima e há mais de 50 anos não sofre intervenção antrópica direta, porém embora não exista extração de lenha para fins domésticos ou comerciais são criados animais (ovinos e bovinos) em seu interior.

\section{Coleta dos dados florísticos e fitossociológico}

Para amostragem do componente arbustivo/ arbóreo adulto foram implantadas 18 unidades amostrais de $10 \times 25 \mathrm{~m}$ de forma sistemática, em cada área, totalizando 36 parcelas, com uma área amostral total de $9.000 \mathrm{~m}^{2}$. Na amostragem da regeneração natural foi implantada uma subparcela $(10 \times 5 \mathrm{~m})$ no interior de cada unidade amostral, totalizando 36 subparcelas, o equivalente a uma área amostral de $1.800 \mathrm{~m}^{2}$.

Em cada parcela foram amostrados e etiqueta- 
dos com placas de PVC todos os indivíduos arbustivo/arbóreos adultos com circunferência a altura do peito $(\mathrm{CAP}) \geq 6 \mathrm{~cm}$. A circunferência foi mensurada com fita métrica e a altura estimada com tesoura de alta poda, com 6 metros de comprimento total.

No levantamento da regeneração natural os indivíduos amostrados foram etiquetados com placas de PVC e após as medições agrupados por classes de altura segundo metodologia proposta por Marangon (1999) e adaptada ao presente trabalho, em que: $\mathrm{C} 1=$ altura $(\mathrm{H}) \geq 0,5 \mathrm{~m}$ até $1,0 \mathrm{~m} ; \mathrm{C} 2=\mathrm{H}>1,0$ até $1,5 \mathrm{~m}$; e $\mathrm{C} 3=\mathrm{H}>1,5 \mathrm{~m}$ e $\mathrm{CNB}<6 \mathrm{~cm}$.

$\mathrm{O}$ reconhecimento das espécies foi realizado com base em conhecimentos empíricos e dendrológicos da equipe de levantamento em campo e com o auxílio do proprietário do terreno. Para a classificação das espécies foi adotado o sistema APG II (2003).

\section{Análise dos dados fitossociológicos}

Para a realização dos cálculos da estrutura horizontal, vertical, diversidade e similaridade florística da vegetação adotou-se as fórmulas apresentadas por Felfili e Rezende (2003) e os cálculos realizados através do software Mata Nativa, versão 2.0.

Foram calculadas as estimativas dos parâmetros, quais sejam: Densidade relativa; Frequência relativa; Dominância relativa; e Valor de importância para os indivíduos adultos.

Os parâmetros estimados dos indivíduos presentes na regeneração natural foram Densidade relativa, Frequência relativa, Estimativa da regeneração natural e Regeneração natural total, todos por classes de altura.

Em ambos os estudos (comunidade arbustivo/ arbórea adulta e regeneração natural) foram realizados os cálculos de diversidade florística e agregação das espécies. Para o cálculo da diversidade florística utilizou-se o índice de diversidade de Shannon $\left(\mathrm{H}^{\prime}\right)$ (MUELLER-DOMBOIS; ELLEMBERG，1974). O delineamento experimental utilizado para análise do índice de diversidade foi em blocos casualizados e os resultados comparados pelo teste de Tukey ao nível de $5 \%$ de significância. O software utilizado foi o Sisvar, versão 5.3 .

Na agregação das espécies, adotou-se o índice de MacGuinnes (SOUZA; SOARES, 2013). Já para as comparações florísticas foi empregada a análise de agrupamento, utilizando como medida a distância euclidiana. Os cálculos foram realizados partindo-se da formação de uma matriz de presença e ausência das espécies, utilizando-se a distância euclidiana como medida de dissimilaridade e o algoritmo de agrupamento de Ward. Para a análise dos dados da similaridade florística utilizou-se o programa Pc-Ord for Windows versão 4.14 (MCCUNE; MEFFORD, 1999).

\section{RESULTADOS E DISCUSSÃO}

\section{Análise fitossociológica da comunidade arbustivo/ arbóreo}

No Ambiente I foram amostrados 286 indivíduos pertencentes a quatro famílias e seis espécies, enquanto que no Ambiente II foram amostrados 1155 indivíduos pertencentes a oito famílias e doze espécies, sendo todas reconhecidas em nível de espécies (Tabela 1).

Tabela 1. Famílias e espécies amostradas no componente arbustivo/arbóreo adulto em duas áreas de Caatinga no município de Cajazeirinhas, Paraíba, com respectivos nomes comuns, hábito e número de indivíduos.

\begin{tabular}{|c|c|c|c|c|}
\hline \multirow[t]{2}{*}{ FAMÍLIA-ESPÉCIE } & \multirow[t]{2}{*}{ N. Comum } & \multirow[t]{2}{*}{ Hábito } & \multicolumn{2}{|c|}{ Número de indivíduos } \\
\hline & & & Ambiente I & Ambiente II \\
\hline \multicolumn{5}{|l|}{ FABACEAE - MIMOSOIDEAE } \\
\hline Mimosa tenuiflora (willd.) Poir. & J. Preta & Árvore & 274 & 37 \\
\hline Piptadenia stipulacea (Benth.) Ducke & J. Branca & Árvore & 1 & 10 \\
\hline Anadenanthera colubrina (Vell.) Brenan & Angico & Árvore & - & 28 \\
\hline FABACEAE - CAESALPINIOIDEAE & & & & \\
\hline Bauhinia cheilantha (Bong.) Stand. & Mororó & Árvore & - & 184 \\
\hline Libidibia ferrea (Mart. ex Tull.) L.P. Queiroz & Pau Ferro & Árvore & 1 & 5 \\
\hline $\begin{array}{c}\text { Poincianella pyramidalis (Tul.) L. P. Queiroz } \\
\text { FABACEAE - FABOIDEAE }\end{array}$ & Catingueira & Árvore & 6 & 66 \\
\hline $\begin{array}{c}\text { Amburana cearensis (Arr.Cam.) A.C.Sm. } \\
\text { EUPHORBIACEAE }\end{array}$ & Cumaru & Árvore & - & 1 \\
\hline $\begin{array}{l}\text { Croton blanchetianus Baill. } \\
\text { COMBRETACEAE }\end{array}$ & Marmeleiro & Arbusto & 2 & 639 \\
\hline $\begin{array}{l}\text { Combretum leprosum Mart. } \\
\text { ANACARDIACEAE }\end{array}$ & Mofumbo & Arbusto & 2 & 98 \\
\hline $\begin{array}{l}\text { Myracrodruon urundeuva Allemão } \\
\text { APOCYNACEAE }\end{array}$ & Aroeira & Árvore & - & 74 \\
\hline $\begin{array}{l}\text { Aspidosperma pyrifolium Mart. } \\
\text { RHAMNACEAE }\end{array}$ & Pereiro & Árvore & - & 10 \\
\hline Ziziphus joazeiro Mart. & Juazeiro & Árvore & - & 3 \\
\hline
\end{tabular}


Ao comparar o número de indivíduos inventariados verificou-se que há uma redução de 75,2\% entre o Ambiente II e Ambiente I, respectivamente, e em relação ao número de famílias e espécies esse valor cai para $50 \%$. Com base nessas informações, percebe-se que embora o Ambiente I tenha sido abandonado há 12 anos, não havendo nenhum tipo de intervenção humana para restaurá-lo, ele apresenta alta resiliência, mesmo com a presença de ovinos e bovinos pastando em seu interior.

Os resultados do presente trabalho se assemelham aos observados por Andrade et al. (2005), ao fazerem análise da cobertura de duas fitofisionomias de caatinga com diferentes históricos de uso no Cariri paraibano, em que foram amostrados 16 espécies e sete famílias na área bem preservada e seis espécies e quatro famílias na área degradada.

Verificou-se na Tabela 1 que no Ambiente I a família com maior número de espécies foi a Fabaceae, com exemplares das subfamílias Mimosoideae e Caesalpinioideae com duas cada. Essa baixa diversidade de famílias e táxons, quando comparado ao Ambiente II, é reflexo das atividades antrópicas realizadas no passado e a herbivoria de animais em seu interior.

No Ambiente II a família com o maior número de espécies também foi a Fabaceae, com as subfamílias Mimosoideae (com três espécies), Caesalpinioideae (com três) e Faboideae (com uma). As demais famílias apresentaram apenas uma. Embora essa área apresente um maior número de famílias e espécies não implica afirmar que ela também não foi perturbada e se encontra em processo de sucessão.

Dentre as espécies amostradas no Ambiente I, a Mimosa tenuiflora apresentou um maior número de indivíduos, correspondente a $95,8 \%$ de todos inventariados. Isso ocorre, segundo Maia (2012), por ser uma espécie heliófita e vicejar terrenos diversos.
Pereira Filho et al. (2005) descreve que essa espécie apresenta certa agressividade quando submetida ao corte e rebrota em qualquer época do ano com grande intensidade. Um fato interessante a se observar é a redução no número de indivíduos de Mimosa tenuiflora, na ordem de $86,5 \%$, se comparada as duas áreas (Ambiente I e Ambiente II). Segundo Maia (2012) isso é justificável, pois a espécie no início do processo de sucessão costuma formar povoamentos puros, e através do processo de deposição e decomposição dos resíduos vegetais daquela ocorre o preparo do solo para o aparecimento de outras plantas mais exigentes como, por exemplos, Libidibia ferrea, Combretum leprosum, Anadenanthera colubrina, dentre outras.

Para o Ambiente II o maior número de indivíduos inventariados foi verificado para o Croton blanchetianus (639), correspondendo a uma diferença de 99,7\% quando comparado ao Ambiente I (2 indivíduos). Segundo Carvalho (2010), uma população extensa dessa espécie é comum em ambientes que estão passando por processo de sucessão vegetal, onde esta se apresenta como uma espécie pioneira por conseguir se desenvolver rapidamente em ambientes com condições adversas. Para Maia (2012), essa espécie é também indicadora do nível de perturbação antrópica, ocorrendo com elevada frequência em lugares com vegetação muito devastada.

$\mathrm{Na}$ Tabela 2 constam alguns parâmetros fitossociológicos calculados para as espécies amostradas nos Ambientes I e II, no qual é verificado que no Ambiente I a espécie Mimosa tenuiflora se encontra com uma densidade relativa (DR) de 95,8\%, mostrando-se superior às demais espécies em todos os parâmetros, e no Ambiente II a espécie Croton blanchetianus se destaca com uma densidade relativa (DR) de 55,3\%.

Tabela 2. Parâmetros fitossociológicos calculados para os indivíduos arbustivo/arbóreos adultos (CAP $\geq 6 \mathrm{~cm}) \mathrm{em}$ duas áreas de Caatinga localizada no município de Cajazeirinhas (PB), em que: DR - densidade relativa (\%); FR - frequência relativa; DoR - dominância relativa; e VI - valor de importância.

\begin{tabular}{ccccccccc}
\hline Espécies & \multicolumn{4}{c}{ Ambiente I } & \multicolumn{4}{c}{ Ambiente II } \\
\cline { 2 - 9 } & DR & FR & DoR & VI & DR & FR & DoR & VI \\
\hline Croton blanchetianus & 0,7 & 11,11 & 0,21 & 7,806 & 55,3 & 14,9 & 37,2 & 107,43 \\
Bauhinia cheilantha & - & - & - & - & 15,9 & 10,7 & 7,88 & 34,553 \\
Combretum leprosum & 0,7 & 11,11 & 0,16 & 7,761 & 8,48 & 14,9 & 8,54 & 31,902 \\
Myracrodruon urundeuva & - & - & - & - & 6,41 & 12,4 & 18,41 & 30,805 \\
Poincianella pyramidalis & 2,1 & 17 & 0,94 & 20,3 & 5,71 & 10,74 & 11,7 & 28,145 \\
Anadenanthera colubrina & - & - & - & - & 2,42 & 10,74 & 10,4 & 23,561 \\
Mimosa tenuiflora & 95,8 & 62,3 & 98,4 & 256,3 & 3,2 & 11,57 & 6,52 & 21,29 \\
Aspidosperma pyrifolium & - & - & - & - & 0,87 & 7,96 & 0,86 & 6,685 \\
Piptadenia stipulacea & 0,35 & 3,45 & 0,1 & 3,896 & 0,87 & 4,13 & 0,5 & 5,5 \\
Ziziphus joazeiro & - & - & - & - & 0,26 & 1,65 & 2,02 & 3,932 \\
Libidibia ferrea & 0,35 & 3,45 & 0,15 & 3,95 & 0,43 & 2,48 & 0,63 & 3,545 \\
Amburana cearensis & - & - & - & - & 0,09 & 0,83 & 1,74 & 2,654 \\
\hline
\end{tabular}

Ao analisar a Tabela 2 verificou-se que no Ambiente I a espécie Mimosa tenuiflora apresentou maior densidade, frequência e dominância relativa. Isso é justificável em função da espécie estar bem distribuída na área, formando inicialmente um povoamento homogêneo e, teoricamente, explorar melhor os recursos propiciados pelo habitat nos estágios iniciais de sucessão ecológica. Ainda nessa área os 
baixos valores observados entre parâmetros para as demais espécies, a princípio, podem ser atribuídos a uma segunda etapa no processo de sucessão decorrente da presença das espécies Libidibia ferrea e Poincianella pyramidalis, as quais são comuns serem inventariadas em ambientes conservados.

No Ambiente II foi verificado que o Croton blanchetianus apresentou densidade relativa superior às demais espécies $(55,3 \%)$. Embora considerada como uma planta pioneira, comum em ambientes antropizados, verificou-se uma dominância relativa alta $(37,2 \%)$, quando comparada com as demais. Entretanto, pode-se afirmar que esse remanescente se encontra em melhor equilíbrio em termos estruturais e florísticos quando comparado ao Ambiente I, principalmente devido ao estabelecimento de espécies que apresentam maior longevidade (Myracrodruon urundeuva, Poincianella pyramidalis, Anadenanthera colubrina, Ziziphus joazeiro, Libidibia ferrea e Amburana cearenses). Holanda (2012), realizando inventario em remanescente de Savana Estépica Florestada, abandonado há mais de 60 anos, porém com extração ilegal de lenha, estaca e mourões, verificou que a espécie Croton blanchetianus também apresentou maior densidade relativa $(53,2 \%)$.

Em relação a Frequência Relativa, no Ambiente II, pode-se observar que apesar da superioridade no número de indivíduos do Croton blanchetianus sobre a Combretum leprosum ambos tiveram frequências iguais, com $14,9 \%$, ou seja, com o passar dos anos existe uma tendência gradativa de substituição e distribuição do número indivíduos na área em função dos princípios ecológicos.

Ainda no Ambiente II observou-se que a
Myracrodruon urundeuva, apesar de ser a quarta espécie com o maior número de indivíduos, apresenta a segunda maior dominância relativa. Esse fato se explica devido a espécie apresentar um maior diâmetro do fuste e já se encontrar estabelecida no remanescente.

Tratando-se do Valor de Importância, verificou-se a superioridade da Mimosa tenuiflora $(256,3)$ no Ambiente I, quando comparada as demais espécies. Para o Ambiente II, verificou-se o domínio do Croton blanchetianus $(107,43)$. No entanto, percebeu -se o início de um equilíbrio paras as demais espécies, com exceção das Aspidosperma pyrifolium, Piptadenia stipulacea, Ziziphus joazeiro, Libidibia ferrea e Amburana cearenses, com 6,68, 5,5, 3,9, 3,5 e 2,6, respectivamente. Para ambas as áreas verificou -se que de modo geral o valor de importância acompanha o comportamento do número de indivíduos, ou seja, as espécies com maior número de indivíduos apresentam os maiores valores de importância.

\section{Distribuição espacial das espécies}

No Ambiente I, a maioria das espécies apresentou padrões de distribuição uniforme, exceto para a espécie Poincianella pyramidalis, que obteve tendência ao agrupamento. No Ambiente II, o índice revelou que a maioria das espécies possui tendência ao agrupamento, com exceção de Bauhinia cheilantha, Anadenanthera colubrina e Poincianella pyramidalis, que obtiveram distribuição agregada, e de Croton blanchetianus, Combretum leprosum e Amburana cearenses, nas quais foi verificado padrão de distribuição uniforme (Tabela 3).

Tabela 3. Índices de agregação de espécies de duas áreas de Caatinga no município de Cajazeirinhas (PB), em que: IGA Índice de McGuinnes; UNI - Uniforme; AGR - Agregada; e TAG - Tendência ao Agrupamento.

\begin{tabular}{cccc}
\hline Espécie & N. Comum & & IGA \\
\cline { 2 - 4 } & & Ambiente I & Ambiente II \\
\hline Croton blanchetianus & Marmeleiro & $\mathrm{UNI}$ & UNI \\
Bauhinia cheilantha & Mororó & - & AGR \\
Combretum leprosum & Mofumbo & $\mathrm{UNI}$ & UNI \\
Anadenanthera colubrina & Angico & - & AGR \\
Poincianella pyramidalis & Caatingueira & TAG & AGR \\
Myracrodruon urundeuva & Aroeira & - & TAG \\
Mimosa tenuiflora & Jurema Preta & UNI & TAG \\
Aspidosperma pyrifolium & Pereiro & - & TAG \\
Piptadenia stipulacea & Jurema Branca & UNI & TAG \\
Ziziphus joazeiro & Juazeiro & - & TAG \\
Libidibia ferrea & Pau Ferro & $\mathrm{UNI}$ & TAG \\
Amburana cearensis & Cumaru & - & UNI
\end{tabular}

Conforme observado na Tabela 3 verificou-se que as espécies Croton blanchetianus e Combretum leprosum apresentaram o mesmo padrão de distribuição espacial (UNI) nas duas áreas, o que supõe, a princípio, que apresentam uma competição intraespecífica pelos recursos propiciados pelo habitat. Para as espécies Mimosa tenuiflora, Piptadenia stipulacea, Libidibia ferrea e Poincianella pyramidalis observou -se mudanças na distribuição espacial entre as áreas
(Ambiente I e Ambiente II), reflexo, talvez, de fases distintas no processo de sucessão ecológica em ambas as áreas e da competição interespecífica.

Segundo Marangon et al. (2013), para entender a distribuição das espécies em sua maioria é preciso compreender que a área de estudo apresenta fatores morfológicos, como os mecanismos de dispersão das espécies a curta distância, fatores ambientais, como solos rasos e distúrbios naturais, além dos 
fatores fitossociológicos, como competição inter e intraespecífica, e levar em consideração que essas características propiciam uma agregação das espécies.

\section{Florística e estrutura da regeneração natural}

Tabela 4. Famílias e espécies amostradas na regeneração natural no município de Cajazeirinhas (PB) com os respectivos nomes vulgares, número de indivíduos por família e percentagem.

\begin{tabular}{|c|c|c|c|}
\hline \multirow[t]{2}{*}{ FAMÍLIA-ESPÉCIE } & \multirow[t]{2}{*}{ N. Comum } & \multicolumn{2}{|c|}{ Número de indivíduos } \\
\hline & & Ambiente I & Ambiente II \\
\hline FABACEAE - MIMOSOIDEAE & & & \\
\hline Mimosa tenuiflora (willd.) Poir. & Jurema Preta & 244 & 2 \\
\hline Piptadenia stipulacea (Benth.) Ducke & J. Branca & - & 5 \\
\hline Anadenanthera colubrina (Vell.) Brenan & Angico & 1 & 12 \\
\hline FABACEAE - CAESALPINIOIDEAE & & & \\
\hline Bauhinia cheilantha (Bong.) Stand. & Mororó & - & 48 \\
\hline Libidibia ferrea (Mart. ex Tull.) L.P. Queiroz & Pau Ferro & 9 & 1 \\
\hline $\begin{array}{l}\text { Poincianella pyramidalis (Tul.) L. P. Queiroz } \\
\text { EUPHORBIACEAE }\end{array}$ & Catingueira & - & 5 \\
\hline $\begin{array}{l}\text { Croton blanchetianus Baill. } \\
\text { COMBRETACEAE }\end{array}$ & Marmeleiro & 99 & 180 \\
\hline $\begin{array}{l}\text { Combretum leprosum Mart. } \\
\text { ANACARDIACEAE }\end{array}$ & Mofumbo & 7 & 10 \\
\hline $\begin{array}{l}\text { Myracrodruon urundeuva Allemão } \\
\text { APOCYNACEAE }\end{array}$ & Aroeira & - & 10 \\
\hline Aspidosperma pyrifolium Mart. & Pereiro & - & 3 \\
\hline
\end{tabular}

$\mathrm{Na}$ regeneração observou-se que houve uma redução no número de espécies em relação ao componente adulto. Para o Ambiente I, duas espécies (Piptadenia stipulacea e Poincianella pyramidalis) amostradas no componente adulto não estiveram presentes na regeneração natural. No entanto, inventariou-se uma nova espécie (Anadenanthera colubrina) que não havia sido amostrada no componente arbustivo/arbóreo adulto. No Ambiente II também houve redução de duas espécies (Ziziphus joazeiro e Amburana cearensis) em relação à amostragem do componente adulto.

Pode-se observar na Tabela 4 que no Ambiente I a espécie com maior número de indivíduos inventariado foi a Mimosa tenuiflora, com $67,7 \%$ de todos os indivíduos amostrados, e para o Ambiente II destacou-se Croton blanchetianus, com 65,2\%. Vale ressaltar que essas espécies também apresentaram maior número de indivíduos no componente adulto
$\mathrm{Na}$ regeneração natural foram inventariados no Ambiente I 360 indivíduos, sendo estes pertencentes a três famílias e cinco espécies. No Ambiente II foram inventariados 276 indivíduos pertencentes a cinco famílias e dez espécies (Tabela 4).

Tabela 5. Estimativas da regeneração natural por classes de altura no Sítio Riachão, município de Cajazeirinhas (PB), em que: DR - Densidade relativa; FR - Frequência relativa; RNC - Regeneração natural; e RNT - Regeneração natural total.

\begin{tabular}{|c|c|c|c|c|c|c|c|c|}
\hline \multirow[t]{3}{*}{ Espécie } & \multicolumn{8}{|c|}{ Parâmetros } \\
\hline & \multicolumn{4}{|c|}{ Ambiente I } & \multicolumn{4}{|c|}{ Ambiente II } \\
\hline & RNC1 & RNC2 & RNC3 & RNT & RNC1 & RNC2 & RNC3 & RNT \\
\hline Mimosa tenuiflora & 57,8 & 61,6 & 72 & 63,8 & 1,68 & - & 2,12 & 1,26 \\
\hline Croton blanchetianus & 30,3 & 28,8 & 21,3 & 26,8 & 57,1 & 55,6 & 49,8 & 54,2 \\
\hline Bauhinia cheilantha & - & - & - & - & 14,1 & 19,7 & 26,9 & 20,2 \\
\hline Myracrodruon urundeuva & - & - & - & - & 9,5 & - & 8,47 & 5,99 \\
\hline Combretum leprosum & 4,68 & 3,04 & 2,28 & 3,33 & 5,41 & 7,42 & 6,36 & 6,39 \\
\hline Anadenanthera colubrina & 2,13 & - & - & 0,71 & 4,09 & 6,56 & 4,24 & 4,96 \\
\hline Aspidosperma pyrifolium & - & - & - & - & 3,73 & - & - & 1,24 \\
\hline Piptadenia stipulacea & - & - & - & - & 2,78 & 2,47 & - & 1,75 \\
\hline Poincianella pyramidalis & - & - & - & - & - & - & - & - \\
\hline Libidibia ferrea & 5,09 & 6,61 & 4,55 & 5,41 & - & - & - & - \\
\hline
\end{tabular}


No Ambiente I as espécies que apresentaram os maiores valores de densidade, frequência e regeneração natural total foram Mimosa tenuiflora, seguida de Croton blanchetianus. Segundo Pereira et al. (2001), essas espécies apresentam características que fazem delas pioneiras típicas da caatinga, tendendo a dominar os primeiros estágios serais, aparecendo, portanto, como as espécies mais comuns nas áreas sob grandes perturbações. A Mimosa tenuiflora, embora seja uma espécie forrageira, apresenta alta capacidade de rebrota, o que lhe permite se adaptar aos primeiros estágios da sucessão ecológica em toda a área. No Ambiente II, as espécies que mais se destacaram na densidade, frequência e regeneração total foram Croton blanchetianus e Bauhinia cheilantha.
Em relação ao número de indivíduos por classe de altura, verifica-se, na Figura 1 que o maior número de exemplares foram amostrados na classe de altura $\mathrm{C} 1$, com 122 indivíduos no Ambiente I e 137 indivíduos no Ambiente II. Na classe C2 e C3 houve uma inversão, no qual fora verificado que o Ambiente I apresenta um maior número de indivíduos, quando comparados ao Ambiente, II com 120 e 62 e, 118 e 77 , respectivamente. Desses indivíduos que estão presentes nas classes $\mathrm{C} 1, \mathrm{C} 2$ e C3, no Ambiente I, a espécie Mimosa tenuiflora contribuiu com 64, 62,5 e $77 \%$, respectivamente, enquanto que no Ambiente II a espécie Croton blanchetianus contribuiu com 69,3, 64,5 e $58,4 \%$, respectivamente.

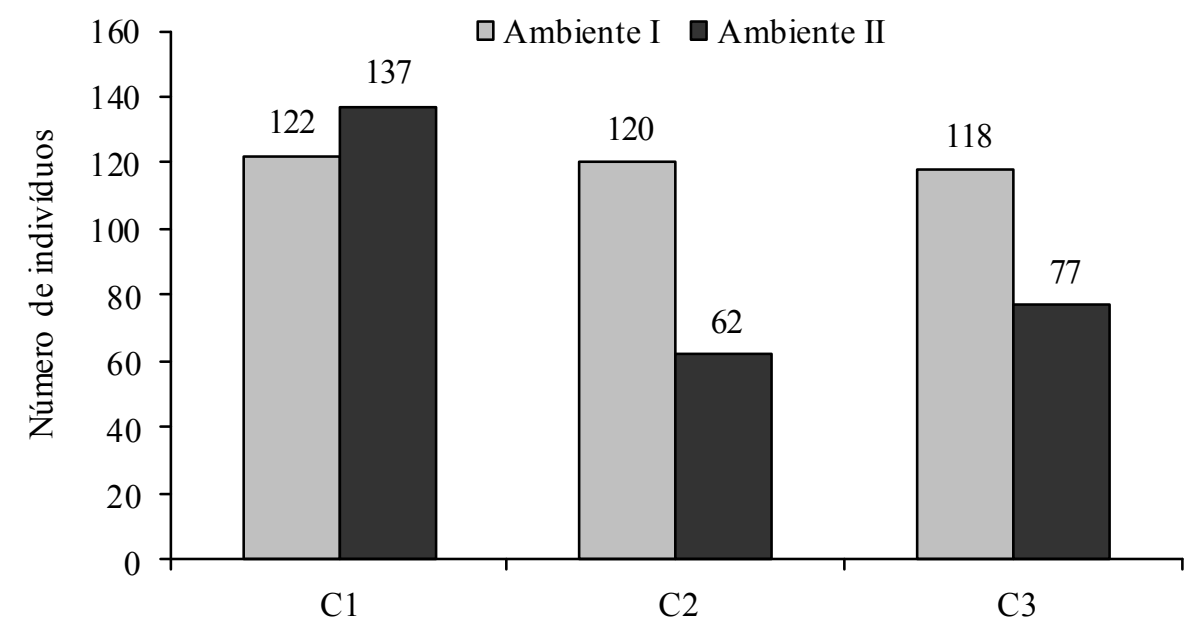

Class es de altura

Figura 1. Número de indivíduos por classe de altura amostrados em duas áreas de Caatinga, em Cajazeirinhas (PB).

Houve expressiva redução no número de indivíduos das classes $\mathrm{C} 1$ a $\mathrm{C} 3$, no Ambiente II, na ordem de $43,8 \%$. A princípio devido a competição intraespecífica e interespecífica entre as espécies, associado ao pastejo dos animais. No Ambiente I o número de indivíduos se manteve relativamente constante, havendo apenas uma pequena redução de 3,3\% entre as classes $\mathrm{C} 1$ e $\mathrm{C} 3$. Resultados semelhantes foram observados por Holanda (2012) em área de Caatinga. $\mathrm{O}$ autor atribui essa redução há uma série de fatores abióticos, bióticos e antrópicos que podem comprometer todo o processo dinâmico da regeneração natural.

\section{Diversidade e similaridade florística (Adulto e regeneração natural)}

A diversidade florística calculada para os indivíduos adultos e regeneração natural entre os dois ambientes são relativamente baixas, quando comparada a outras áreas de Caatinga com diferentes níveis de perturbação (Tabela 6).

Tabela 6. Índice de diversidade de espécies arbustivo-arbórea adulta e regeneração natural em áreas de Caatinga com diferentes históricos de perturbação.

\begin{tabular}{ccc}
\hline Componente & \multicolumn{3}{c}{$\mathrm{H}^{\prime}\left(\right.$ nats.ind $\left.^{-1}\right)$} \\
\cline { 2 - 3 } & Ambiente I & Ambiente II \\
\hline Adulto & $0,23 \mathrm{~b}$ & $1,50 \mathrm{a}$ \\
Regeneração natural & $0,80 \mathrm{~b}$ & $1,21 \mathrm{a}$ \\
\hline
\end{tabular}

Embora esse valor (Ambiente II) seja semelhante aos valores calculados por Holanda (2012), Maracajá et al., (2003) e Andrade et al., (2005), que foram de 1,67, 1,29 e 1,51 nats.ind ${ }^{-1}$, respectivamen- te, os mesmos são muito baixos. Isso é reflexo do nível de antropização que cada um foi submetido. No Ambiente I, o índice de diversidade foi aquém, se comparado ao Ambiente II, 0,23 nats.ind ${ }^{-1}$, reflexo 
do processo histórico de perturbação da área.

Para a regeneração natural do Ambiente I e Ambiente II foram calculados os índices de 0,8 e 1,21 nats.ind $^{-1}$, respectivamente. Segundo Holanda (2012), essa redução da diversidade pode estar relacionada com o processo de sucessão, ocasionado pela competição interespecífica e principalmente pelas atividades pastoris.
A Figura 2 é representada por um dendrograma, que representa a similaridade florística entre o Ambiente I e Ambiente II para os indivíduos adultos (Amb I A e Amb II A) e regeneração natural (Amb I $\mathrm{R}$ e Amb II R). Observando a imagem, verifica-se a formação de dois grupos, ficando claro as diferenças florísticas entre os dois ambientes, tanto para os indivíduos adultos quanto para a regeneração natural.

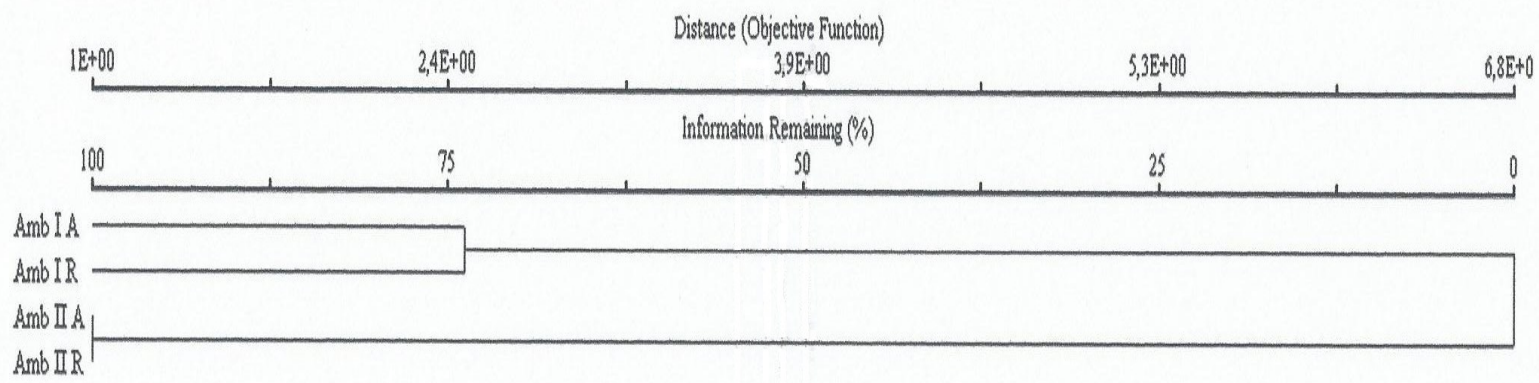

Figura 2. Dendrograma de similaridade florística pelo Método de Ward baseado na distância euclidiana entre indivíduos adulto (Amb I e II A) e regeneração natural (Amb I e II R).

Embora os ambientes apresentem diferentes históricos de perturbação percebe-se que o componente animal interfere de forma significativa na estrutura e diversidade da vegetação adulta e regeneração natural, principalmente em áreas abertas, que se encontram nos estágios iniciais de sucessão. Áreas em estágio de sucessão inicial na região semiárida, quando comparada a outras regiões do país, costumam ter menor densidade, frequência e dominância de indivíduos e são tenros e palatáveis (uma parte), consequentemente sofrem interferência (herbivoria) e não conseguem se estabelecer no fragmento.

\section{CONCLUSÃO}

Animais domesticados influenciam diretamente na estrutura e diversidade de espécies arbustivo-arbóreas adultas e regeneração natural, principalmente se as áreas se encontrarem nos estágios iniciais de sucessão ecológica.

Em estágio inicial de sucessão, para essa área, percebe-se a tendência na formação de povoamento floristicamente homogêneo, com dominância de indivíduos da espécie Mimosa tenuiflora.

\section{REFERÊNCIAS}

ANGIOSPERM PHYLOGENY GROUP III. An update of the Angiosperm Phylogeny Group classification for the orders and families of flowering plants. Botanical Journal of the Linnean Society, London, v. 16, [s.n], p. 105 - 121, 2009.

AESA - Agência executiva de gestão das águas do estado da Paraíba. Monitoramento de chuvas acumuladas. Disponível em: <http:// http:// site2.aesa.pb.gov.br/aesa/ monitoramentoPluviometria.do? metodo=listarChuvasAnuaisAtual $>$. Acesso em 04 de abril de 2011.

ANDRADE, L. A. et al. Análise da cobertura de duas fitofisionomias de caatinga, com diferentes históricos de uso, no município de São João do Cariri, Estado da Paraíba. Revista Cerne, Lavras, v. 11, n. 3, p. 253-262, 2005.

ANDRADE, L. A.; FABRICANTE, J. R.; ARAÚJO, E. L. Estudos de fitossociologia em vegetação de Caatinga. In: FELFILI, J. M.; EISENLOHR, P.V.; MELO, M.M.R.F.; ANDRADE, L.A.; MEIRA NETO, J.A.A. Fitossociologia no Brasil: métodos e estudo de caso. Viçosa: UFV, 2011. cap. 12, p. 339371.

ANDRADE-LIMA, D. Plantas das Caatingas. Rio de Janeiro: ACADEMIA BRASILEIRA DE CIÊNCIAS, 1989. 243 p.

CORRÊA, M. M. et al. Atributos físicos, químicos e mineralógicos de solos da região das varzeas de Sousa (PB). Revista Brasileira de Ciência do solo, Viçosa, v. 27, n. 2, p. 311-324, 2003.

COSTA, C. C. A. et al. Análise comparativa da produção de serapilheira em fragmentos arbóreos e arbustivos em área de caatinga na flona de Açu-RN. Revista Árvore, Viçosa, v. 34, n. 2, p. 259-265, 2010 .

DANTAS, J. G. et al. Estrutura do componente ar- 
bustivo/arbóreo de uma área de Caatinga situada no município de Pombal-PB. Revista Verde, Mossoró, v. 5, n. 1, p. $134-142,2010$.

EMPRESA BRASILEIRA DE PESQUISA AGROPECUÁRIA. Sistema brasileiro de classificação de solos. 2.ed. Rio de Janeiro: EMBRAPA SOLO, 2006. 306 p.

HOLANDA, E. M.; SOUTO, L. S. Estrutura, deposição e ciclagem de nutrientes em um remanescente de caatinga, na região de Pombal - PB. In: VIII CONGRESSO DE INICIAÇÃO CIENTÍFICA DA UFCG, 2011, Campina Grande. Anais... Campina Grande: UFCG, 2011.

FELFILI, J. M.; REZENDE, R. P. Conceitos e métodos em fitossociologia. Brasília: Universidade de Brasília, 2003. 68 p. (Comunicações técnicas florestais, v.5, n.1)

HOLANDA, A. C. Estrutura da comunidade arbustivo-arbórea e suas interações com o solo em uma área de caatinga, Pombal-PB. 2012. 164 f. Tese (Doutorado em Ciências Florestais: Área de concentração em Ecologia e Conservação de Ecossistemas Florestais) - Universidade Federal Rural de Pernambuco, Recife, PE. 2012.

MAIA, G. N. Caatinga: árvores e arbustos e suas utilidades. 2. ed. Fortaleza, CE: PRINTCOLOR GRÁFICA E EDITORA, 2012. 413 p.

MARACAJÁ, P. B. et al. Levantamento florístico e fitosociológico do extrato arbustivo- arbóreo de dois ambientes na Vila Santa Catarina, Serra do Mel, RN. Revista de Biologia e Ciências da Terra, Campina Grande, v. 3, n. 2, p. 25-32, 2003.

MARANGON, G. P. et al. Estrutura e padrão espacial da vegetação em uma área de caatinga. Revista Floresta, Curitiba, v. 43, n. 1, p. 83 - 92, 2013.

MCCUNE, B.; MEFFORD, M. J. PC-ORD version 4.14: multivariate analysis of ecological data. Lincoln, Oregon: MJM SOFTWARE DESIGN, 1999. $237 \mathrm{p}$.

MUELLER-DOMBOIS, D.; ELLEMBERG, H. Aims and methods of vegetation ecology. New York City, Nova Iorque: JOHN WILEY E SONS, 1974. 547 p.

PEREIRA FILHO, J. M. et al. Correlação entre o teor de tanino e a degradabilidade ruminal da matéria seca e proteína bruta do feno de Jurema preta (Mimosa tenuiflora Wild.) tratada com hidróxido de sódio. Livestock Research for Rural Development, Cali, v. 17, n. 8, 2005.
PEREIRA, I. M. et al. Regeneração natural em um remanescente de caatinga sob diferentes níveis de perturbação, no agreste paraibano. Acta Botânica Brasílica, Belo Horizonte, v. 15, n. 3, p. 431-426, 2001.

SANTANA, J. A. S. Estrutura fitossociológica, produção de serapilheira e ciclagem de nutrientes em uma área de Caatinga no Seridó do Rio Grande do Norte. 2005. 206 f. Tese (Doutorado em Agronomia em área de concentração em Ecologia, Manejo e Conservação de Recursos Naturais ) - Universidade Federal da Paraíba, Areia, 2005.

SOUZA, A. L.; SOARES, C. P. B. Florestas nativas: estrutura, dinâmica e manejo. Viçosa, MG: EDITORA UFV, 2013. 322 p. 